Check for updates

Cite this: RSC Adv., 2017, 7, 40650

Received 20th May 2017

Accepted 15th August 2017

DOI: $10.1039 / \mathrm{c} 7 \mathrm{ra05700h}$

rsc.li/rsc-advances

\section{One-step in situ synthesis of strontium ferrites and strontium ferrites/graphene composites as microwave absorbing materials $\dagger$}

\begin{abstract}
Wei Chen, Qingyun Liu, (D) Xixi Zhu and Min Fu (DD*
Strontium ferrites/graphene $\left(\mathrm{SrFe}_{12} \mathrm{O}_{19} / \mathrm{G}\right)$ composites were synthesized by a facile one-step surfactant assisted hydrothermal method. The structure, magnetic properties and electromagnetic parameters of the as-prepared composites were evaluated. Uniform $\mathrm{SrFe}_{12} \mathrm{O}_{19}$ nanoparticles with a diameter of 60$70 \mathrm{~nm}$ were well distributed on the graphene. The formation of $\mathrm{SrFe}_{12} \mathrm{O}_{19}$ nanoparticles and the reduction of graphene oxide were accomplished simultaneously. The re-stacking of graphene sheets and the aggregation of $\mathrm{SrFe}_{12} \mathrm{O}_{19}$ nanoparticles were inhibited. The as-obtained composites exhibited better absorbing properties than the pristine $\mathrm{SrFe}_{12} \mathrm{O}_{19}$ particles due to the synergistic effect of $\mathrm{SrFe}_{12} \mathrm{O}_{19}$ and graphene. The minimum reflection loss (RL) of $\mathrm{SrFe}_{12} \mathrm{O}_{19} / \mathrm{G}$ composites with the thickness of $3 \mathrm{~mm}$ reached $-34.8 \mathrm{~dB}$ at $13.6 \mathrm{GHz}$, and the effective absorption bandwidth ( $\mathrm{RL}<-10 \mathrm{~dB}$ ) was $5.7 \mathrm{GHz}$. However, the minimum $\mathrm{RL}$ of the $\mathrm{SrFe}_{12} \mathrm{O}_{19}$ particles only reached $-13.5 \mathrm{~dB}$, and the effective absorption bandwidth was $4.6 \mathrm{GHz}$. A possible mechanism for the enhanced absorbing performance was proposed.
\end{abstract}

\section{Introduction}

The wide application of electromagnetic technology facilitates people's work and life. However, the electromagnetic pollution which results from the overuse of electromagnetic technology has become a new form of environmental pollution in addition to those such as noise, waste water, exhaust gas and solid waste. Over the last few decades, researchers have been trying to find effective ways to prevent electromagnetic pollution and protect information security and human health. ${ }^{1}$ Consequently, absorbing materials have emerged, which can absorb the incident electromagnetic waves and attenuate them in the form of heat. ${ }^{2}$ The traditional absorbing materials cannot meet all of the requirements, including tiny thickness, light weight, broad bandwidth and strong absorption. Therefore, combining two or more kinds of functional materials is widely regarded as a feasible way to improve the absorbing performances. ${ }^{3,4}$

As a kind of useful electromagnetic functional material, ferrites have aroused enormous research interests in many fields, with applications such as magneto-optical devices, magnetic memories, sensitive elements, catalysts, biology, absorbing materials and so on. ${ }^{5-11}$ As a typical hard magnetic material discovered in 1950s, strontium ferrite $\left(\mathrm{SrFe}_{12} \mathrm{O}_{19}\right)$ is of

College of Chemical and Environmental Engineering, Shandong University of Science and Technology, Qingdao 266590, P. R. China. E-mail: fumin@sdust.edu.cn; fuminis@163.com; Fax: +86-532-80681197; Tel: +86-532-86057757

$\dagger$ Electronic supplementary information (ESI) available. See DOI: 10.1039/c7ra05700h great importance due to its low cost production, high saturation magnetization and good chemical stability. ${ }^{12}$

A number of different methods, including co-precipitation method, ${ }^{13}$ high temperature calcinations, ${ }^{14}$ sol-gel method ${ }^{15}$ and hydrothermal reaction followed by post-calcination, ${ }^{16}$ have been used to develop $\mathrm{SrFe}_{12} \mathrm{O}_{19}$ based materials. However, the preparation of $\mathrm{SrFe}_{12} \mathrm{O}_{19}$ often suffers from the agglomeration, which is caused by the magnetic dipole interaction between ferrite particles. ${ }^{17}$ Moreover, single component functional material cannot meet the ever-increasing demands for absorbing materials. Hence, combining $\mathrm{SrFe}_{12} \mathrm{O}_{19}$ with another suitable component would be a feasible way to solve the above mentioned problems.

Graphene, a single layer of carbon atoms patterned in a hexagonal lattice, has attracted worldwide attentions owing to its two dimensional structure, high specific surface area, super electronic, mechanical and thermal properties. ${ }^{18,19}$ Considering the excellent properties of graphene and $\mathrm{SrFe}_{12} \mathrm{O}_{19}, \mathrm{SrFe}_{12} \mathrm{O}_{19} /$ graphene $\left(\mathrm{SrFe}_{12} \mathrm{O}_{19} / \mathrm{G}\right)$ hybrids can be very attractive for microwave absorbing applications. On one hand, graphene with planar structure provides an ideal platform for the growth of $\mathrm{SrFe}_{12} \mathrm{O}_{19}$, suppressing the aggregation of $\mathrm{SrFe}_{12} \mathrm{O}_{19}$ nanoparticles. On the other hand, $\mathrm{SrFe}_{12} \mathrm{O}_{19}$ nanoparticles on the surface of graphene inhibit the re-stacking of graphene. The structural stability guarantees the good electromagnetic properties.

Luo et $a .^{20}$ prepared reduced graphene oxide/strontium ferrite/polyaniline (RGO/SF/PANI) composites by a three-step method. Firstly, they obtained $\mathrm{SrFe}_{12} \mathrm{O}_{19}$ nanoparticles by coprecipitation and post-calcination method. Secondly, they 
mixed $\mathrm{SrFe}_{12} \mathrm{O}_{19}$ nanoparticles with graphene oxide (GO) solution and obtained $\mathrm{RGO} / \mathrm{SrFe}_{12} \mathrm{O}_{19}$ hybrids. Finally, in situ polymerization method was used to obtain RGO/SF/PANI composites. Zhao et al. ${ }^{21}$ synthesized $\mathrm{RGO} / \mathrm{SrFe}_{12} \mathrm{O}_{19}$ nanoflakes composites by a two-step method. They separately prepared $\mathrm{SrFe}_{12} \mathrm{O}_{19}$ nanoflakes and RGO, and subsequently mixed them to obtain the composites. The absorption properties were also investigated. However, there are few reports focused on the construction of $\mathrm{SrFe}_{12} \mathrm{O}_{19}$ /graphene composites by a one-step in situ method.

Herein we synthesize the $\mathrm{SrFe}_{12} \mathrm{O}_{19} / \mathrm{G}$ composites by a onestep hydrothermal reaction with the assistance of the surfactant. The formation of $\mathrm{SrFe}_{12} \mathrm{O}_{19}$ and the reduction of GO are accomplished simultaneously, which is much different from two-step method. ${ }^{20,21}$ Also, post-calcinations are not needed in our experiment, avoiding the introduction of impurities, and saving energy and time. ${ }^{\mathbf{1 6}}$ Moreover, the planar structure of graphene and the use of surfactant restrain the aggregation of $\mathrm{SrFe}_{12} \mathrm{O}_{19}$ nanoparticles. ${ }^{3}$ In addition, the applications of pristine ferrites are limited due to large densities and narrow absorbed frequency. Graphene is light-weight and highly conductive, which offers the possibility of satisfying the everincreasing demands for absorbing materials. ${ }^{22}$ The structure, morphology and absorbing properties of as-prepared hybrids were investigated. The minimum reflection loss (RL) of $\mathrm{SrFe}_{12} \mathrm{O}_{19} / \mathrm{G}$ composites at the thickness of $3 \mathrm{~mm}$ reached -34.8 $\mathrm{dB}$ at $13.6 \mathrm{GHz}$, which was much better than that of the pristine $\mathrm{SrFe}_{12} \mathrm{O}_{19}$ particles $(-13.5 \mathrm{~dB})$. It is believed that the assynthesized composites can find applications in the microwave absorbing field.

\section{Experimental}

\section{Materials}

Natural flake graphite (325 mesh) was purchased from Beijing Creative Biological Engineering Materials Co. Ltd. Strontium chloride $\left(\mathrm{SrCl}_{2} \cdot 6 \mathrm{H}_{2} \mathrm{O}, 99.9 \%\right)$ and Iron(III) chloride hexahydrate $\left(\mathrm{FeCl}_{3} \cdot 6 \mathrm{H}_{2} \mathrm{O}, 99.9 \%\right)$ were purchased from Aladdin. All other reagents and solvents were purchased from Beijing Chemicals. All chemicals used in our experiments were reagent grade and used without further purification.

\section{Preparation of the $\mathrm{SrFe}_{12} \mathrm{O}_{19} / \mathrm{G}$ composites}

Graphene oxide (GO) was synthesized from natural flake graphite by a modified Hummers method as reported elsewhere. ${ }^{17}$ The detailed procedure is described as follows: $\mathrm{FeCl}_{3} \cdot 6 \mathrm{H}_{2} \mathrm{O}$ and $\mathrm{SrCl}_{2} \cdot 6 \mathrm{H}_{2} \mathrm{O}$ (the atomic ratio of $\mathrm{Fe} / \mathrm{Sr}=12$ ) were mixed in $40 \mathrm{~mL}$ of deionized water under magnetic stirring. After complete dissolution, $0.5 \mathrm{~g}$ of polyvinylpyrrolidone (PVP) was added into the above solution with ultrasonication for $0.5 \mathrm{~h}$. Then, $0.05 \mathrm{~g}$ of GO was slowly added into the mixture solution and dispersed by ultrasonication for $0.5 \mathrm{~h}$. Subsequently, $4 \mathrm{~g}$ of $\mathrm{NaOH}$ was slowly added into $20 \mathrm{~mL}$ of ammonia solution (28\% mass concentration, purchased and used without further processing) with mild agitation in an ice bath. Then the aqueous solution containing $0.1 \mathrm{~mol}$ of $\mathrm{NaOH}$ and $0.294 \mathrm{~mol}$ of ammonia was obtained. The freshly prepared mixed solution containing $\mathrm{NaOH}$ and ammonia was used to adjust the $\mathrm{pH}$ value of above precursor solution to 13 . Finally, the mixture was transferred to a $80 \mathrm{~mL}$ Teflon-lined autoclave, sealed and maintained at $220^{\circ} \mathrm{C}$ for $6 \mathrm{~h}$. The autoclave was then naturally cooled to room temperature and the black precipitate was collected, washed, and dried under vacuum at $80{ }^{\circ} \mathrm{C}$ for $12 \mathrm{~h}$.

\section{Characterization}

The field emission scanning electron microscopy (FESEM) was performed with a Hitachi S-4800 microscope operated at $15 \mathrm{kV}$. Transmission electron microscopy (TEM) was carried out using a Hitachi HT7700 microscope. Fourier transform infrared spectroscopy (FTIR) was recorded on a Bruker VECTOR 22 spectrometer in the frequency range of $4000-500 \mathrm{~cm}^{-1}$. X-ray diffraction (XRD) patterns were recorded on a X-ray diffractometer (Ultima IV) at $40 \mathrm{kV}$ and $150 \mathrm{~mA}$ with $\mathrm{Cu} \mathrm{K}_{\alpha}$ radiation. The composition and chemical states of samples were investigated by X-ray photoelectron spectroscopy (XPS, PHI 5300X). The magnetic properties were measured using a vibrating sample magnetometer (VSM, Lakeshore 7300) in the field of $20 \mathrm{kOe}$. Vector network analyzer (HP 8722ES) was used to measure the complex permittivity and permeability of the composites in 1-18 GHz.

\section{Results and discussion}

Fig. 1 displayed representative TEM and HRTEM images of the $\mathrm{GO}, \mathrm{SrFe}_{12} \mathrm{O}_{19}$ particles and $\mathrm{SrFe}_{12} \mathrm{O}_{19} / \mathrm{G}$ composites. It can be seen from Fig. 1a that the GO had a two dimensional planar structure with wrinkles and folds on the edges. The pure $\mathrm{SrFe}_{12} \mathrm{O}_{19}$ particles showed the typical irregular agglomerated particle morphology in Fig. 1b. The sizes of $\mathrm{SrFe}_{12} \mathrm{O}_{19}$ particles reached up to several microns. As revealed by the TEM images of as-prepared composites (Fig. 1c and d), the whole graphene sheets were decorated by plenty of homogeneous nanoparticles with a diameter of 60-70 $\mathrm{nm}$. And no obvious aggregation was observed, which was different from the pure $\mathrm{SrFe}_{12} \mathrm{O}_{19}$ particles.

Fig. 1e illustrated the HRTEM image of GO and the lattice spacing of GO was $0.83 \mathrm{~nm}$. Both the lattice fringes of graphene and $\mathrm{SrFe}_{12} \mathrm{O}_{19}$ nanoparticles were clearly observable in Fig. 1f. The lattice spacing of graphene was $0.36 \mathrm{~nm}$, smaller than that of GO, indicating the removal of the oxygen-containing functional groups. ${ }^{1}$ The lattice fringe distances of about $0.26 \mathrm{~nm}$ and about $0.27 \mathrm{~nm}$ were indexed to the (114) and (107) planes of $\mathrm{SrFe}_{12} \mathrm{O}_{19}$, respectively. The clear lattice indicated that $\mathrm{SrFe}_{12} \mathrm{O}_{19}$ nanoparticles were of high crystallinity.

Graphene with planar structure provided an ideal platform for the growth of $\mathrm{SrFe}_{12} \mathrm{O}_{19}$ nanoparticles, and the existence of $\mathrm{SrFe}_{12} \mathrm{O}_{19}$ nanoparticles inhibited the re-stacking of graphene. Therefore, it was safe to deduce that the introduction of graphene overcame the poor dispersion of $\mathrm{SrFe}_{12} \mathrm{O}_{19}$ particles in the composites. The structural uniformity indicated the good electromagnetic properties and potential microwave absorbing applications of the $\mathrm{SrFe}_{12} \mathrm{O}_{19} / \mathrm{G}$ composites.

Fig. 2 showed FTIR spectra of the GO and $\mathrm{SrFe}_{12} \mathrm{O}_{19} / \mathrm{G}$ composites. The peaks of GO located at 3409, 1738, 1625, 1399 


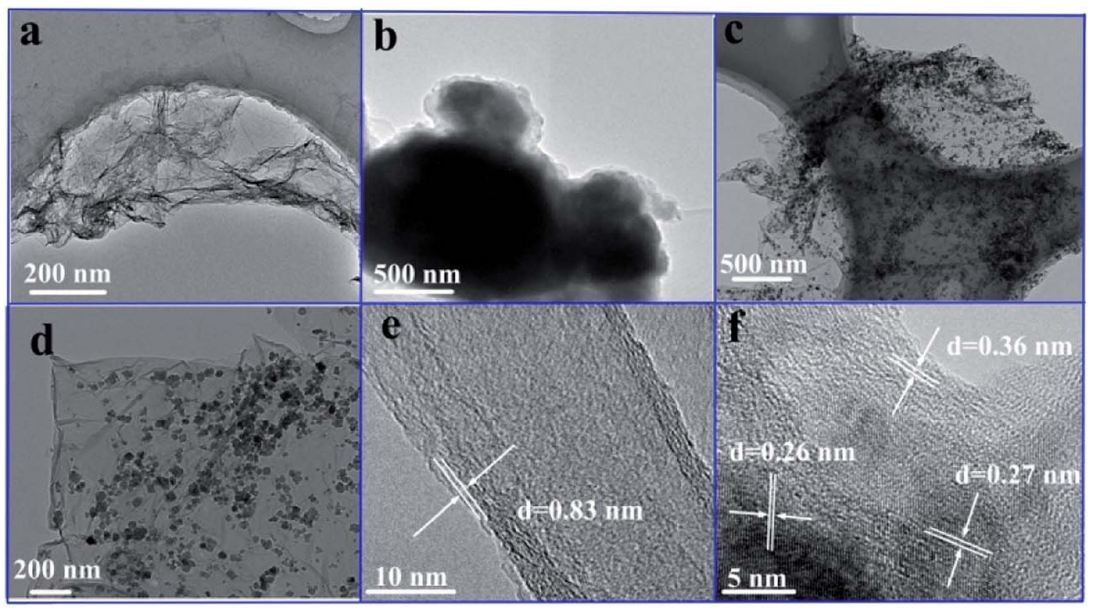

Fig. 1 TEM images of the GO (a), $\mathrm{SrFe}_{12} \mathrm{O}_{19}$ particles (b), $\mathrm{SrFe}_{12} \mathrm{O}_{19} / \mathrm{G}$ composites (c and d), HRTEM images of the GO (e) and $\mathrm{SrFe}{ }_{12} \mathrm{O}_{19} / \mathrm{G}$ composites (f).

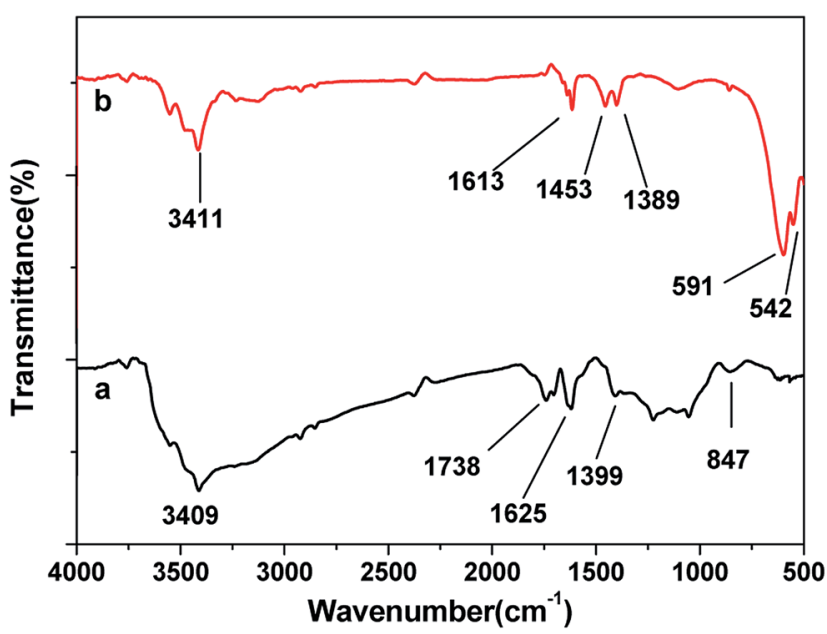

Fig. 2 FTIR spectra of the (a) GO and (b) $\mathrm{SrFe}_{12} \mathrm{O}_{19} / \mathrm{G}$ composites.

and $847 \mathrm{~cm}^{-1}$ were due to the vibration and deformation bands of $\mathrm{O}-\mathrm{H}, \mathrm{C}=\mathrm{O}$ stretching vibrations from carbonyl groups, $\mathrm{C}=\mathrm{C}$ configurable vibrations from the aromatic zooms, $\mathrm{C}-\mathrm{OH}$ stretching vibrations, $\mathrm{C}-\mathrm{O}$ vibrations from epoxy groups and alkoxy groups, respectively. ${ }^{18}$ However, most of the peaks related to the oxygen-containing functional groups disappeared in the FTIR spectrum of $\mathrm{SrFe}_{12} \mathrm{O}_{19} / \mathrm{G}$ composites (Fig. 2b), revealing that these oxygen-containing functional groups were almost removed after the hydrothermal reaction. The hydrothermal condition with ammonia provided thermal and chemical factors to reduce the GO. The peaks at $1613 \mathrm{~cm}^{-1}$ were attributed to the $\mathrm{C}=\mathrm{C}$ configurable vibrations from the graphene, peaks at 1453 and $1389 \mathrm{~cm}^{-1}$ exhibited the stretching vibration and deformation vibration of hydroxy group. Moreover, an additional peak at 591 and $542 \mathrm{~cm}^{-1}$ in Fig. $2 \mathrm{~b}$ could be ascribed to lattice absorption of $\mathrm{Fe}-\mathrm{O}$, further confirming the existence of $\mathrm{SrFe}_{12} \mathrm{O}_{19} \cdot{ }^{19}$

As shown in Fig. 3a, a sharp peak at $2 \theta=10.6^{\circ}$ can be indexed to the (001) crystallographic plane of the GO. However, it vanished and a new characteristic (002) diffraction peak appeared at $2 \theta=25.1^{\circ}$ after the hydrothermal reduction (Fig. 3b). It was noteworthy that the broadening and weakening of the (002) diffraction peak of graphene was obvious, indicating the reduction process cannot restore graphene to the highly ordered crystal structure of graphite. The $\mathrm{SrFe}_{12} \mathrm{O}_{19}$ and $\mathrm{SrFe}_{12} \mathrm{O}_{19} / \mathrm{G}$ composites exhibited the very similar diffraction peaks, as shown in Fig. $3 \mathrm{c}$ and d. And the Rietveld refinement of XRD patterns of $\mathrm{SrFe}_{12} \mathrm{O}_{19} / \mathrm{G}$ composites was shown in Fig. S1. $\dagger$ The (001) crystallographic plane of the GO disappeared in the XRD pattern of $\mathrm{SrFe}_{12} \mathrm{O}_{19} / \mathrm{G}$ composites, suggesting the reduction of GO after the hydrothermal reaction. ${ }^{3}$ Nevertheless, no (002) diffraction peak of graphene appeared, which may be caused by two reasons. First of all, the in situ growth of $\mathrm{SrFe}_{12} \mathrm{O}_{19}$ nanoparticles on the graphene inhibited the restacking of graphene layers during the reduction process, weakening its diffraction intensity. Moreover, the diffraction peak of graphene was easy to be suppressed by $\mathrm{SrFe}_{12} \mathrm{O}_{19}$ due to the loading content of graphene in the composites. ${ }^{23,24}$ All

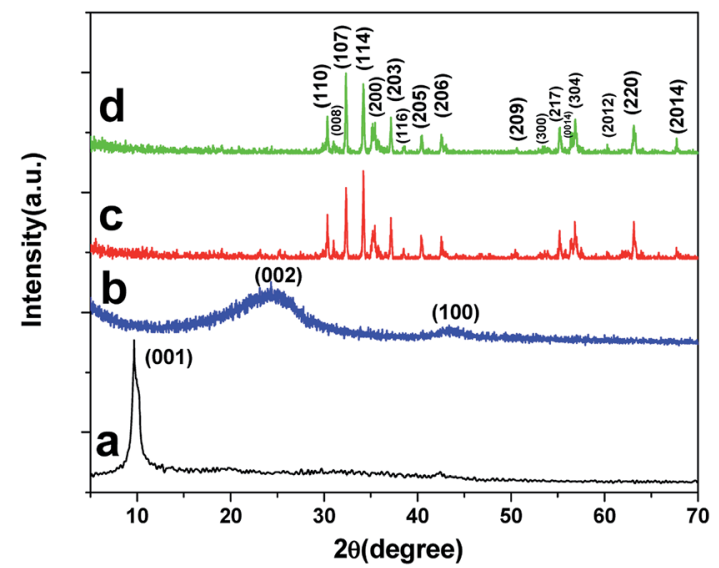

Fig. 3 XRD patterns of the (a) GO, (b) graphene, (c) $\mathrm{SrFe}_{12} \mathrm{O}_{19}$ and (d) $\mathrm{SrFe}_{12} \mathrm{O}_{19} / \mathrm{G}$ composites. 
labeled diffraction peaks in the range of $5-70^{\circ}$ can be indexed to the hexagonal $\mathrm{SrFe}_{12} \mathrm{O}_{19}$ (PDF card no. 33-1340) crystallites. $^{25,26}$ The sharp diffraction peaks and high intensity indicated the good crystallinity of as-obtained composites.

XPS was also employed to analyze GO and the $\mathrm{SrFe}_{12} \mathrm{O}_{19} / \mathrm{G}$ composites. The wide scan XPS spectrum (Fig. 4a) of the $\mathrm{SrFe}_{12} \mathrm{O}_{19} / \mathrm{G}$ composites showed photoelectron lines at a binding energy of 133.1, 284.6, 530.2 and 710.9 eV attributed to $\mathrm{Sr} 3 \mathrm{~d}, \mathrm{C} \mathrm{1s}, \mathrm{O} 1 \mathrm{~s}$ and Fe 2p, respectively. The inset in Fig. 4b showed the $\mathrm{C} 1 \mathrm{~s}$ of $\mathrm{GO}$, which consisted of two main components arising from $\mathrm{C}-\mathrm{C} / \mathrm{C}=\mathrm{C}(284.6 \mathrm{eV})$ and $\mathrm{C}-\mathrm{O}(286.6 \mathrm{eV})$ groups and two minor components from $\mathrm{C}=\mathrm{O}(288.2 \mathrm{eV})$ and $\mathrm{O}-\mathrm{C}=\mathrm{O}(289.4 \mathrm{eV})$ groups. ${ }^{3,17}$ Compared with GO, the $\mathrm{C} 1 \mathrm{~s}$ of $\mathrm{SrFe}_{12} \mathrm{O}_{19} / \mathrm{G}$ composites varied dramatically. The content of $\mathrm{C}-\mathrm{O}$ group decreased rapidly, and peaks of $\mathrm{C}=\mathrm{O}$ and $\mathrm{O}-\mathrm{C}=\mathrm{O}$ groups even disappeared, suggesting a remarkable reduction after the hydrothermal reaction. In Fig. $4 \mathrm{c}$, the $\mathrm{Sr} 3 \mathrm{~d}_{5 / 2}$ signal appeared at $133.3 \mathrm{eV}$, and the peak at $134.9 \mathrm{eV}$ was ascribed to the $\mathrm{Sr} 3 \mathrm{~d}_{3 / 2}$ level. Fig. $4 \mathrm{~d}$ showed the spectrum of $\mathrm{Fe} 2 \mathrm{p}$ region. The peaks of $\mathrm{Fe} 2 \mathrm{p}_{3 / 2}$ and $\mathrm{Fe} 2 \mathrm{p}_{1 / 2}$ were located at 711.6 and $724.8 \mathrm{eV}$, respectively. All the above analysis indicated the successful synthesis of the $\mathrm{SrFe}_{12} \mathrm{O}_{19} / \mathrm{G}$ composites.

Magnetic hysteresis loops of the $\mathrm{SrFe}_{12} \mathrm{O}_{19} / \mathrm{G}$ composites and $\mathrm{SrFe}_{12} \mathrm{O}_{19}$ particles were shown in Fig. 5. The saturation magnetization and coercivity of the $\mathrm{SrFe}_{12} \mathrm{O}_{19}$ particles were

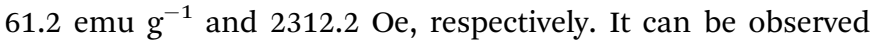
that the saturation magnetization dropped dramatically with the introduction of nonmagnetic graphene. For the $\mathrm{SrFe}_{12} \mathrm{O}_{19} / \mathrm{G}$ composites, the saturation magnetization and coercivity were $41.6 \mathrm{emu} \mathrm{g}^{-1}$ and 1695.6 Oe, respectively.

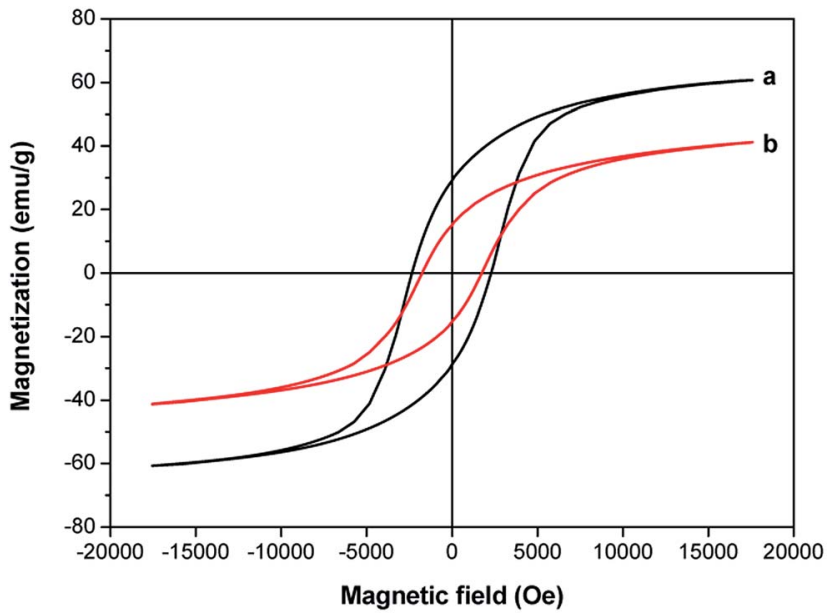

Fig. 5 Magnetic hysteresis loops for (a) $\mathrm{SrFe}_{12} \mathrm{O}_{19}$ particles and (b) $\mathrm{SrFe}_{12} \mathrm{O}_{19} / \mathrm{G}$ composites.

A vector network analyzer was used to measure the electromagnetic parameters of the as-prepared $\mathrm{SrFe}_{12} \mathrm{O}_{19} / \mathrm{G}$ composites in the frequency range of 1-18 GHz. The complex permittivity and complex permeability of the $\mathrm{SrFe}_{12} \mathrm{O}_{19} / \mathrm{G}$ composites and the $\mathrm{SrFe}_{12} \mathrm{O}_{19}$ particles are shown in Fig. 6 and 7 , respectively. As we know, the real part of complex permittivity $\left(\varepsilon^{\prime}\right)$ and complex permeability $\left(\mu^{\prime}\right)$ stand for the storage ability of electromagnetic energy, and the imaginary part of complex permittivity $\left(\varepsilon^{\prime \prime}\right)$ and complex permeability $\left(\mu^{\prime \prime}\right)$ represent the electromagnetic energy loss ability. ${ }^{27}$ For the $\mathrm{SrFe}_{12} \mathrm{O}_{19} / \mathrm{G}$ composites, the $\varepsilon^{\prime}$ showed an approximately constant around
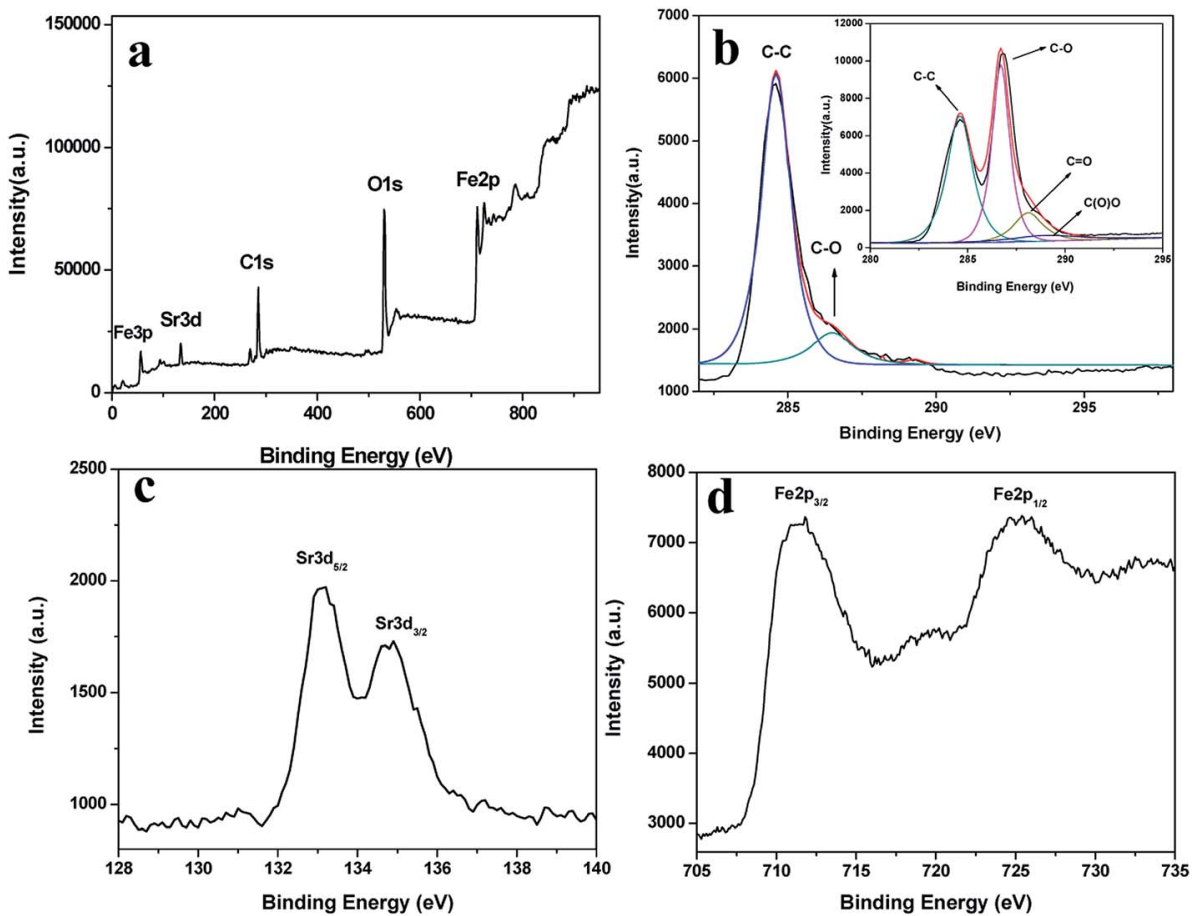

Fig. 4 XPS spectra of the (a) survey scan, (b) $\mathrm{C} 1 \mathrm{~s}$ region (the inset shows $\mathrm{C} 1 \mathrm{~s}$ of $\mathrm{GO}$ ), (c) $\mathrm{Sr} 3 \mathrm{~d}$ region, (d) $\mathrm{Fe} 2 \mathrm{p}$ region of the $\mathrm{SrFe}{ }_{12} \mathrm{O}_{19} / \mathrm{G}$ composites. 

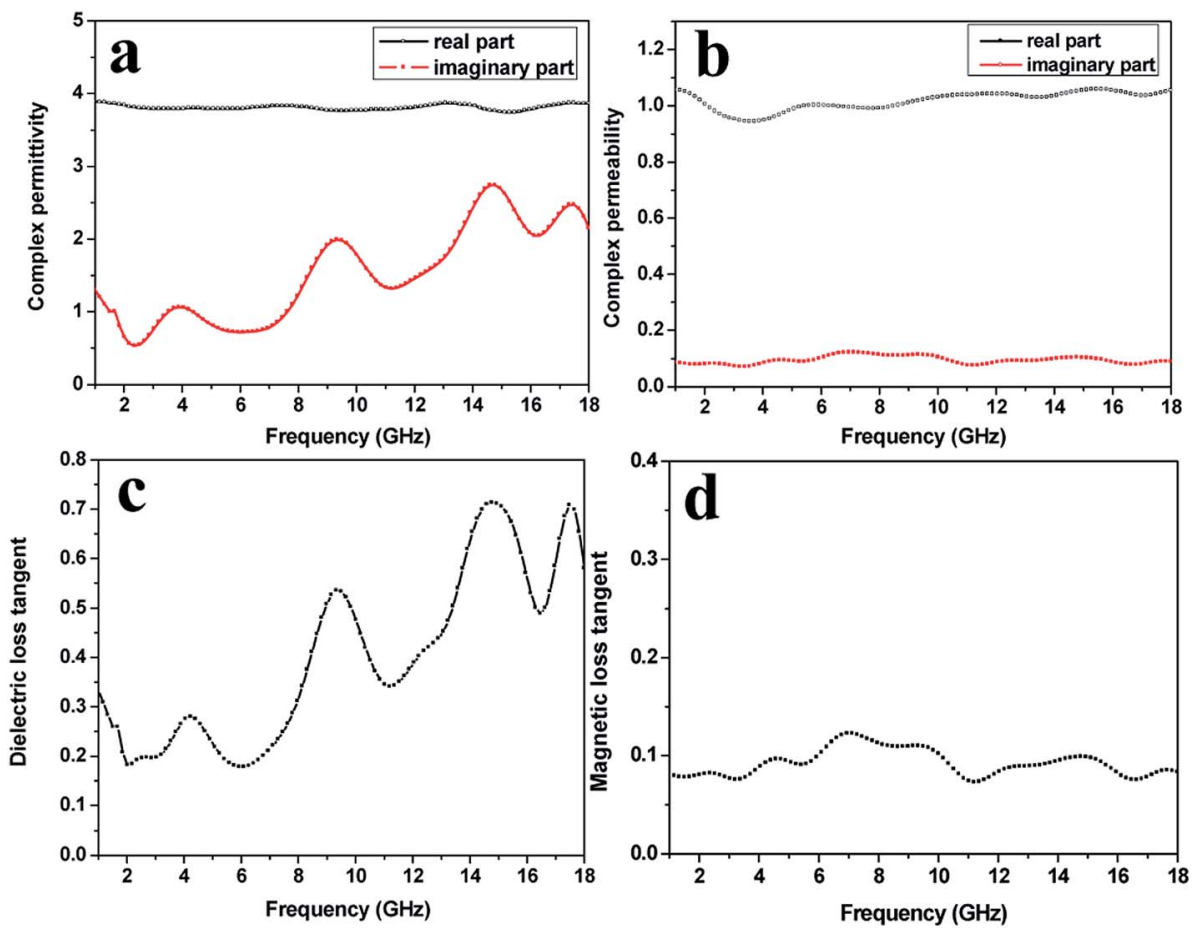

Fig. 6 The complex permittivity (a), complex permeability (b), dielectric loss tangent (c), magnetic loss tangent (d) of the SrFe ${ }_{12} \mathrm{O}_{19} / \mathrm{G}$ composites.

3.9 in the range of $1-18 \mathrm{GHz}$, while the $\varepsilon^{\prime \prime}$ exhibited four high fluctuations from 0.5 to 2.7 in the whole frequency range. According to free electron theory, ${ }^{28} \varepsilon^{\prime \prime} \approx 1 / 2 \pi \varepsilon_{0} \rho f$, where $\rho$ is the resistivity. It can be speculated that the lower $\varepsilon^{\prime \prime}$ values represent higher electric resistivity. In general, the high electric resistivity is in favor of building a balance between complex permeability and complex permittivity, thus decreasing the reflection coefficient of the absorbing materials. Meanwhile, the $\mu^{\prime}$ and $\mu^{\prime \prime}$ changed gently in the range of 1-18 GHz. $\mu^{\prime}$ and $\mu^{\prime \prime}$ maintained at around 1.0 and 0.1 , respectively. The dielectric loss tangent indicates the inherent dissipation of electromagnetic energy for dielectric materials. It can be seen from Fig. $6 \mathrm{c}$ that the
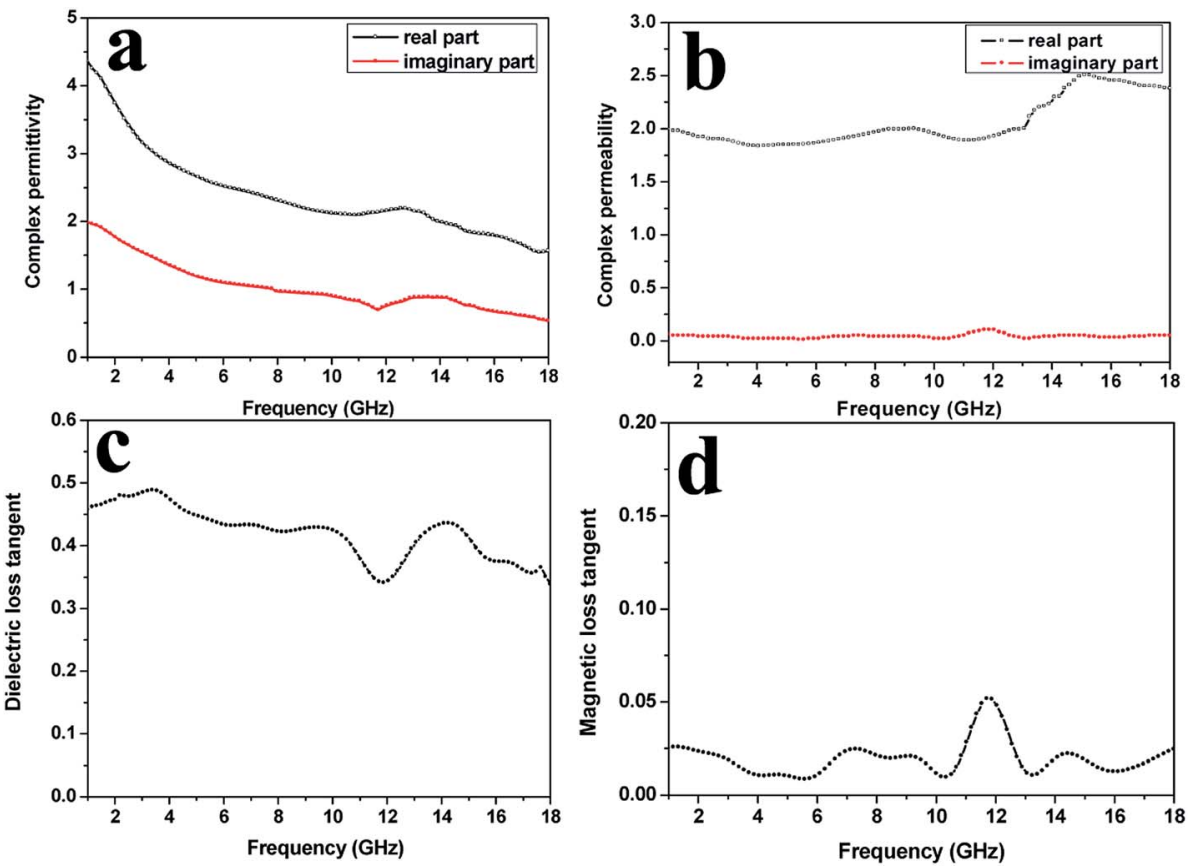

Fig. 7 The complex permittivity (a), complex permeability (b), dielectric loss tangent (c), magnetic loss tangent (d) of the $\mathrm{SrFe}_{12} \mathrm{O}_{19}$ particles. 
dielectric loss tangent showed a similar variation tendency with $\varepsilon^{\prime \prime}$. Four sharp peaks appeared at 4.4, 9.9, 15.1 and $17.5 \mathrm{GHz}$, and the peak values were $0.29,0.54,0.73$ and 0.71 , respectively. Meanwhile, the magnetic loss tangent increased from 0.08 to 0.13 at the $1.0-7.1 \mathrm{GHz}$ range, and decreased from 0.13 to 0.08 over 7.1-18.0 GHz. Apart from dielectric loss and magnetic loss, another significant factor affecting electromagnetic wave absorption is impedance match characteristic, too high permittivity of absorber is detrimental to the impedance match and results in strong reflection and weak absorption.

The complex permittivity, complex permeability, dielectric loss tangent and magnetic loss tangent of the $\mathrm{SrFe}_{12} \mathrm{O}_{19}$ particles are shown in Fig. 7a-d, respectively. Both the $\varepsilon^{\prime}$ and $\varepsilon^{\prime \prime}$ showed a downward trend in the range of 1-18 GHz, declining from 4.4 and 2.0 to 1.6 and 0.6 , respectively. The $\mu^{\prime}$ kept unchanged around 2.0 in the range of $1.0-13.2 \mathrm{GHz}$, and then went up to 2.3 over $13.2-18.0 \mathrm{GHz}$. The $\mu^{\prime \prime}$ remained constant at about 0.08 in the whole frequency range. Compared with the $\mathrm{SrFe}_{12} \mathrm{O}_{19} / \mathrm{G}$ composites, the $\mathrm{SrFe}_{12} \mathrm{O}_{19}$ particles exhibited much lower dielectric loss tangent (less than 0.5) and magnetic loss tangent (around 0.025). Thus, it would be safe to conclude that the $\mathrm{SrFe}_{12} \mathrm{O}_{19} / \mathrm{G}$ composites exhibited better electromagnetic properties than the $\mathrm{SrFe}_{12} \mathrm{O}_{19}$ particles.

The RL can be calculated from the complex permeability and complex permittivity at the given absorber thickness and frequency using the following equations:

$$
\mathrm{RL}(\mathrm{dB})=20 \log \left|\frac{Z_{\text {in }}-1}{Z_{\text {in }}+1}\right|
$$

While the normalized input impedance $\left(Z_{\text {in }}\right)$ is calculated by:

$$
Z_{\text {in }}=\sqrt{\frac{\mu_{\mathrm{r}}}{\varepsilon_{\mathrm{r}}}} \tanh \left(\mathrm{j} \frac{2 \pi f d}{c} \sqrt{\mu_{\mathrm{r}} \varepsilon_{\mathrm{r}}}\right)
$$

where $f$ is the electromagnetic wave frequency, $d$ is the thickness of the absorb layer, $c$ is the velocity of electromagnetic wave in vacuum. $\varepsilon_{\mathrm{r}}$ and $\mu_{\mathrm{r}}$ are the relative complex permittivity and permeability, respectively, which can be calculated by:

$$
\varepsilon_{\mathrm{r}}=\varepsilon^{\prime}-\mathrm{j} \varepsilon^{\prime \prime}, \mu_{\mathrm{r}}=\mu^{\prime}-\mathrm{j} \mu^{\prime \prime}
$$

The RL curves of the $\mathrm{SrFe}_{12} \mathrm{O}_{19}$ particles and the $\mathrm{SrFe}_{12} \mathrm{O}_{19} / \mathrm{G}$ composites with different thicknesses are shown in Fig. 8. The
$\mathrm{RL}$ is expected to be as low as possible at a given sample thickness. The minimum $\mathrm{RL}$ of the $\mathrm{SrFe}_{12} \mathrm{O}_{19}$ particles at the thickness of $4 \mathrm{~mm}$ reached $-13.5 \mathrm{~dB}$, and the effective absorption frequency ( $\mathrm{RL}<-10 \mathrm{~dB}$ ) ranged from 12.9 to 17.5 GHz. However, for the $\mathrm{SrFe}_{12} \mathrm{O}_{19} / \mathrm{G}$ composites, the minimum $\mathrm{RL}$ of $-34.8 \mathrm{~dB}$ was observed at $13.6 \mathrm{GHz}$ with a thickness of $3 \mathrm{~mm}$, and the effective absorption frequency ranged from 11.7 to $17.4 \mathrm{GHz}$. All these analysis suggested that the $\mathrm{SrFe}_{12} \mathrm{O}_{19} / \mathrm{G}$ composites exhibited much better microwave absorbing properties than the $\mathrm{SrFe}_{12} \mathrm{O}_{19}$ particles.

The related literatures based on $\mathrm{SrFe}_{12} \mathrm{O}_{19}$ were listed in Table 1. Wang et al. ${ }^{29}$ synthesized $\mathrm{SrFe}_{12} \mathrm{O}_{19}-\mathrm{MWCNTs}$ composites with different MWCNTs content by sol-gel method. The results indicated that $6 \mathrm{wt} \% \mathrm{SrFe}_{12} \mathrm{O}_{19}-\mathrm{MWCNTs}$ composites possessed the best magnetic and wave absorbing properties. Poorbafrani et al. ${ }^{30}$ firstly prepared $\mathrm{SrFe}_{12} \mathrm{O}_{19}$ by sol-gel method, then combined with different concentrations of $\mathrm{ZnO}$ and obtained $\mathrm{SrFe}_{12} \mathrm{O}_{19} / \mathrm{ZnO}$ composites. They found the reflection loss (RL) in the $\mathrm{Ku}$ frequency band $(12-18 \mathrm{GHz}$ ) was enhanced by up to $5 \mathrm{~dB}$ for $15 \%$ of $\mathrm{ZnO}$ in the nanocomposites. Chen et al. ${ }^{31}$ synthesized $\mathrm{SrFe}_{12} \mathrm{O}_{19} / \mathrm{ZnFe}_{2} \mathrm{O}_{4}$ composites with different weight ratios of $\mathrm{SrFe}_{12} \mathrm{O}_{19}$ to $\mathrm{ZnFe}_{2} \mathrm{O}_{4}$ using sol-gel technique. The composite powder with 15 wt\% $\mathrm{ZnFe}_{2} \mathrm{O}_{4}$ possessed good microwave absorption properties. The minimum $\mathrm{RL}$ of the composite powder reached $-37 \mathrm{~dB}$ at the thickness of $2.2 \mathrm{~mm}$. He et $a .^{32}$ synthesized a new type of conductive and magnetic $\mathrm{PANI} / \mathrm{Ag} / \mathrm{SrFe}_{12} \mathrm{O}_{19}$ composites via three-step method. The RL of the composites was below $-10 \mathrm{~dB}$ between $8.7 \mathrm{GHz}$ and $12.1 \mathrm{GHz}$, with a minimum loss value of

Table 1 Overview of absorbing properties for different $\mathrm{SrFe}_{12} \mathrm{O}_{19}$ based composites

\begin{tabular}{llll}
\hline \multicolumn{3}{c}{ Parameters } & \\
\cline { 2 - 4 } Samples & $\begin{array}{l}\text { Minimum } \\
\mathrm{RL}(\mathrm{dB})\end{array}$ & $\begin{array}{l}\text { Frequency } \\
(\mathrm{GHz})\end{array}$ & $\begin{array}{l}\text { Effective } \\
\text { bandwidth }(\mathrm{GHz})\end{array}$ \\
\hline $\mathrm{SrFe}_{12} \mathrm{O}_{19}-\mathrm{MWCNTS}$ & -19.7 & 3.2 & Not mentioned \\
$\mathrm{SrFe}_{12} \mathrm{O}_{19} / \mathrm{ZnO}$ & -15.47 & 8.37 & Not mentioned \\
$\mathrm{SrFe}_{12} \mathrm{O}_{19} / \mathrm{ZnFe}_{2} \mathrm{O}_{4}$ & -37 & 8.7 & 3.9 \\
$\mathrm{PANI} / \mathrm{Ag} / \mathrm{SrFe}_{12} \mathrm{O}_{19}$ & -14.86 & 9.98 & 3.4 \\
$\mathrm{Sr}_{1-x} \mathrm{La}_{x} \mathrm{Fe}_{12} \mathrm{O}_{19}$ & -41.7 & 9.0 & 4 \\
$\mathrm{This} \mathrm{work}$ & -34.8 & 13.6 & 5.7
\end{tabular}
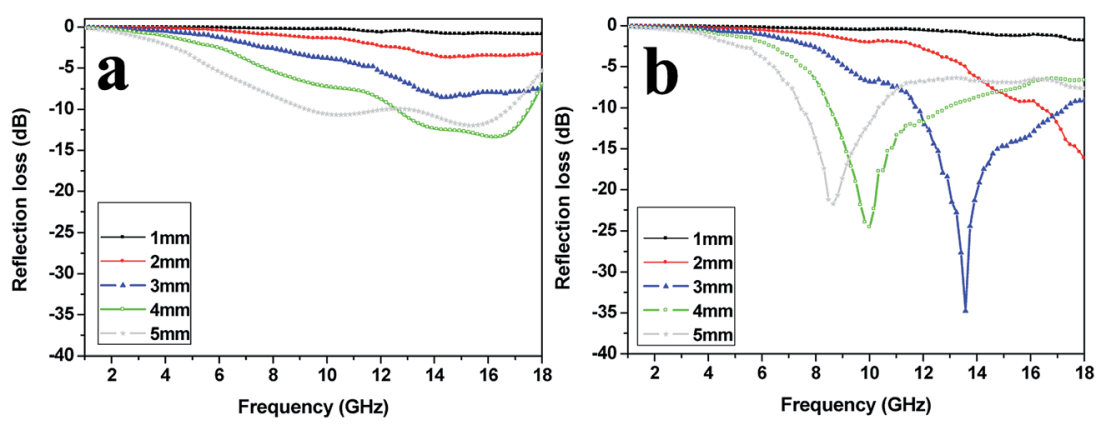

Fig. 8 The calculated reflection loss of (a) the $\mathrm{SrFe}_{12} \mathrm{O}_{19}$ particles, (b) the $\mathrm{SrFe}_{12} \mathrm{O}_{19} / \mathrm{G}$ composites with different thicknesses. 


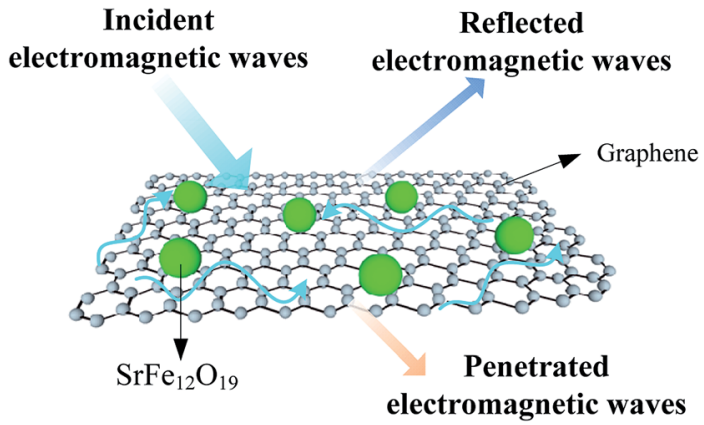

Fig. 9 Schematic diagram of absorbing mechanism for $\mathrm{SrFe}_{12} \mathrm{O}_{19} / \mathrm{G}$ composites.

-14.86 at $9.98 \mathrm{GHz}$. Chen et $a .^{33}$ prepared lanthanum substituted strontium ferrite $\mathrm{Sr}_{1-x} \mathrm{La}_{x} \mathrm{Fe}_{12} \mathrm{O}_{19}(x=0.05,0.1$, $0.15,0.2)$ by a sol-gel process. The results showed that the minimum $\mathrm{RL}$ of the $\mathrm{Sr}_{1-x} \mathrm{La}_{x} \mathrm{Fe}_{12} \mathrm{O}_{19}(x=0.15)$ reached -41.7 $\mathrm{dB}$ with the $-10 \mathrm{~dB}$ bandwidth over $4 \mathrm{GHz}$ at the thickness of $2.3 \mathrm{~mm}$.

The enhanced absorbing properties of as-obtained composites can be attributed to three reasons. First of all, the conductive graphene with two dimensional planar structures constructed an effective conductive network in the composites, providing high dielectric loss tangent. ${ }^{\mathbf{1 7}}$ Moreover, the well dispersion of homogenous $\mathrm{SrFe}_{12} \mathrm{O}_{19}$ nanoparticles on the graphene support ensured the pronounced absorbing performances. In addition, interface scattering could be generated owing to the difference in complex permittivity between graphene and $\mathrm{SrFe}_{12} \mathrm{O}_{19}$ nanoparticles, leading to more efficient absorption of electromagnetic waves. The absorbing mechanism diagram of $\mathrm{SrFe}_{12} \mathrm{O}_{19} / \mathrm{G}$ composites was illustrated in Fig. 9.

\section{Conclusions}

In summary, the $\mathrm{SrFe}_{12} \mathrm{O}_{19} / \mathrm{G}$ composites were synthesized by a one-step in situ surfactant-assisted hydrothermal method. The homogeneous $\mathrm{SrFe}_{12} \mathrm{O}_{19}$ nanoparticles with a typical diameter of 60-70 nm were well anchored on graphene without aggregation. The minimum RL of $-34.8 \mathrm{~dB}$ was observed at $13.6 \mathrm{GHz}$ with a thickness of $3 \mathrm{~mm}$, and the effective absorption bandwidth was $5.7 \mathrm{GHz}$. The synergistic effect of $\mathrm{SrFe}_{12} \mathrm{O}_{19}$ and graphene made a great contribution to the improved absorbing properties. The $\mathrm{SrFe}_{12} \mathrm{O}_{19} / \mathrm{G}$ composites exhibited better absorbing performance than the $\mathrm{SrFe}_{12} \mathrm{O}_{19}$ particles, and showed a promising prospect as absorbing materials.

\section{Conflicts of interest}

There are no conflicts to declare.

\section{Acknowledgements}

This work was financially supported by the National Natural Science Foundation of China (Grant No. 21271119). Shandong University of Science \& Technology is gratefully acknowledged.

\section{References}

1 M. Fu, Q. Z. Jiao and Y. Zhao, Mater. Charact., 2013, 86, 303.

2 V. M. Petrov and V. V. Gagulin, Inorg. Mater., 2001, 37, 93.

3 M. Fu, Q. Z. Jiao and Y. Zhao, J. Mater. Chem. A, 2013, 1, 5577.

4 W. Chen, Q. Y. Liu, X. X. Zhu and M. Fu, Appl. Organomet. Chem., 2017, DOI: 10.1002/aoc.4017.

5 Y. W. Wang, L. D. Zhang and G. W. Meng, J. Phys. Chem. B, 2002, 106, 2502.

6 Q. Y. Liu, Y. T. Yang, H. Li, R. R. Zhu, Q. Shao, S. G. Yang and J. J. Xu, Biosens. Bioelectron., 2015, 64, 147.

7 L. F. Sun, Y. Y. Ding and Y. L. Jiang, Sens. Actuators, B, 2017, 239, 848.

8 S. Ruhle, A. Y. Anderson, H. N. Barad, B. Kupfer, Y. Bouhadana, E. Rosh-Hodesh and A. Zaban, J. Phys. Chem. Lett., 2012, 3, 3755.

9 D. Sando, Y. R. Yang, E. Bousquet, C. Carrétéro, V. Garcia, S. Fusil, D. Dolfi, A. Barthélémy, P. Ghosez, L. Bellaiche and M. Bibes, Nat. Commun., 2016, 7, 1.

10 M. M. Shirolkar, C. Hao, X. Dong, T. Guo, L. Zhang, M. Li and H. Wang, Nanoscale, 2014, 6, 4735.

11 S. H. Hsieh, R. S. Solanki, Y. F. Wang, Y. C. Shao, S. H. Lee, C. H. Yao, C. H. Du, H. T. Wang, J. W. Chiou, Y. Y. Chin, H. M. Tsai, J. L. Chen, C. W. Pao, C. M. Cheng, C. W. Chen, H. J. Lin, J. F. Lee, F. C. Chou and H. M. Tsai, Sci. Rep., 2017, 7, 161.

12 A. L. Xia, C. H. Zuo, L. Chen, C. G. Jin and Y. H. Lv, J. Magn. Magn. Mater., 2013, 332, 186.

13 G. Asghar and M. Anis, J. Alloys Compd., 2012, 526, 85.

14 X. S. Liu, L. Fernandez-Garcia, F. Hu, D. R. Zhu, M. Suárez and J. L. Menéndez, Mater. Chem. Phys., 2012, 133, 961.

15 A. Ghasemi, J. Magn. Magn. Mater., 2012, 324, 1375.

16 J. F. Wang, C. B. Ponton and I. R. Harris, J. Magn. Magn. Mater., 2001, 234, 233.

17 X. Tang and Y. G. Yang, Appl. Surf. Sci., 2009, 255, 9381.

18 K. S. Novoselov, A. K. Geim, S. V. Morozov, E. W. Hill, P. Blake, M. I. Katsnelson and K. S. Novoselov, Science, 2004, 306, 666.

19 A. K. Geim, Science, 2009, 324, 1530.

20 J. Luo, P. Shen, W. Yao and C. Jiang, Nanoscale Res. Lett., 2016, 11, 141.

21 C. Y. Zhao, M. Y. Shen, Z. X. Li, R. Sun, A. L. Xia and X. G. Liu, J. Alloys Compd., 2016, 689, 1037.

22 M. Fu, Q. Z. Jiao, Y. Zhao and H. S. Li, J. Mater. Chem. A, 2014, 2, 735 .

23 A. V. Murugan, T. Muraliganth and A. Manthiram, Chem. Mater., 2009, 21, 5004.

24 X. A. Fan, J. G. Guan, X. F. Cao, W. Wang and F. Z. Mou, Eur. J. Inorg. Chem., 2010, 2010, 419.

25 C. S. Lin, C. C. Hwang, T. H. Huang, G. P. Wang and C. H. Peng, Mater. Sci. Eng., B, 2007, 139, 24.

26 M. M. Hessien, M. M. Rashad and K. El-Barawy, J. Magn. Magn. Mater., 2008, 320, 336.

27 X. F. Zhang, P. F. Guan and X. L. Dong, Appl. Phys. Lett., 2010, 96, 223111. 
28 X. F. Zhang, X. L. Dong, H. Huang, B. Lv and C. J. Choi, J. Phys. D: Appl. Phys., 2007, 40, 5383.

29 W. T. Wang, Q. L. Li and C. B. Chang, Synth. Met., 2011, 161, 32 Z. He, S. H. Qi, X. L. Zhong, H. Ma, P. Wang and H. Qiu, J. 44.

30 A. Poorbafrani, P. Kameli and H. Salamati, J. Mater. Sci., 2013, 48, 186.
31 N. Chen, G. H. Mu, X. F. Pan, K. K. Gan and M. Y. Gu, Mater. Sci. Eng., B, 2007, 139, 256.

Alloys Compd., 2015, 621, 194.

33 N. Chen, K. Yang and M. Y. Gu, J. Alloys Compd., 2010, 490, 609. 